\title{
Seismic Coupling Effect Research on Tubular Busbar Connected Knob Insulator Type UHV Transformation Equipment
}

\author{
Zhubing Zhu, Yongfeng Cheng, Zhicheng Lu, Sheng Li, Min Zhong, Zhenlin \\ Liu \\ China Electric Power Research Institute, China \\ *zzbyx2008@163.com
}

Keywords: single equipment; coupling system; seismic coupling effect; seismic performance evaluation

\begin{abstract}
According to finite element analysis software, this paper established numerical model for the UHV electrical single equipment and interconnect equipments in loop system, and made comparison on seismic performance for the single and interconnect equipments, at last proposed evaluation requirements of seismic performance for the UHV single equipment and loop system.
\end{abstract}

\section{Forewords}

China is currently in a large-scale construction stage of ultra high voltage projects, in which the significance of seismic safety of substation electrical equipment is obvious. However, restrained by the testing conditions for the time being (mainly restraints of plant building height and table top size), it is only possible to conduct seismic capacity test of single UHV equipment without support under most circumstances. In the design of UHV substations in China, some of the open arranged equipment systems (such as HV reactor and main transformer circuit systems, etc.) are using hard tubular busbars to connect the lightning arrester, insulator and mutual inductors among other equipment. Such kind of structure system gives rise to very obvious mutual dynamic coupling effect under the action of earthquake, which can dramatically magnify the dynamic response of the equipment connected with. Therefore, whether seismic capacity of single equipment validated by seismic test can still meet the seismic capacity requirements of the circuit system remains to be further investigated and validated.

Under the action of the same earthquake, seismic capacity of single equipment only has to do with the mechanical property of the equipment itself. However, seismic capacity of the coupling equipment is related not only to the performance of the equipment itself, but also to the connection method, tubular busbar rigidity, tubular busbar span as well as mechanical property of the equipment connected with. To understand the relationship between seismic capacity of single equipment and that of the tubular busbar connected equipment system, it is necessary to conduct an in-depth study of presently commonly seen circuit systems so as to identify the range of influence of such coupling effect, which can provide a reference when evaluating seismic capacity of single equipment, making sure that it meets the seismic operating requirements. In recent years, many scholars in China have conducted tests and theoretical study of seismic capacity of tubular busbar connected knob insulator type transformation equipment circuit system. In 1996, Dastous conducted the dynamic performance test of flexible busbars used for connecting the substation equipment, and studied the impact of flexible busbar geometry on the equipment under the action of earthquake and carried out a finite element simulation of flexible busbar rigidity; in 1999, Kiureghian et al. from University of California Berkeley, USA investigated the nonlinearity of busbar expansion joint, the result of which indicated that deformation and energy consumption of the expansion joint would reduce the dynamic response of the HF equipment in a coupling system; China Electric Power Research Institute investigated the seismic capacity of the interconnected equipment in a UHV circuit system, and the analysis result indicated that after the circuit system is formed through interconnection of the various equipment, frequency of the circuit system decreased when compared with single equipment, and that the seismic response is related to frequency, mass and rigidity, etc. of the circuit system. When frequency of the 
circuit system is consistent with or close to the predominant frequency of the seismic wave, resonance would occur, when the equipment had to withstand the maximum stress. Under the action of pure seismic acceleration response spectrum, the stress magnification coefficient of the circuit system on single equipment may be up to 1.5 with a mean value being around 1.2. Therefore, when evaluating the seismic capacity of a circuit system in an actual project, stresses produced by a number of factors must be taken into account on a comprehensive basis, including combination support, fittings connecting method, weights of various connecting elements and external loads, etc. A Chinese research institution has analyzed the seismic vulnerability of tubular busbar connected substation electrical equipment, the result of which indicated that in the coupling system, dynamic response of the coupling system when the expansion joint was connected with LF equipment as smaller than the dynamic response when the expansion joint was connected with HV equipment.

To further study the mutual coupling effects of the transformation equipment in a UHV circuit system, this paper, by taking a typical HV reactor circuit system as an example, will explore the dynamic response pattern of the coupling system, so as to provide a reference opinion for seismic capacity assessment of UHV power transformation equipment.

\section{Introduction to typical UHV circuit system}

Cross-sections of UHV reactor circuit with 4 knobs and 5 knobs are as shown in Fig. 1, where the 4-knob option shown in Fig. 1(a) has lightning arrester and mutual inductor supports at a spacing of $8.5 \mathrm{~m}$, which are respectively connected with tubular busbar by using tubular busbar fixed fittings and tubular busbar sliding fittings, and the GIS bush and HV reactor bush are subject to flexible coupling with the circuit system. In Fig. 1(b), the 5-knob option has lightning arrester and mutual inductor supports at a spacing of $12.5 \mathrm{~m}$, which are respectively connected with tubular busbar by using tubular busbar sliding fittings and tubular busbar fixed fittings, and the GIS bush, mutual inductor and HV reactor bushes are subject to flexible coupling with the circuit system. In all these options, the tubular busbar has a sectional dimension of $\Phi 250 / 234$ and the tubular busbar center is $18 \mathrm{~m}$ from the ground level. In the figures, length direction along the tubular busbar is Direction X, while Direction Y is horizontally perpendicular to the tubular busbar direction and Direction $\mathrm{Z}$ is the circuit height direction.

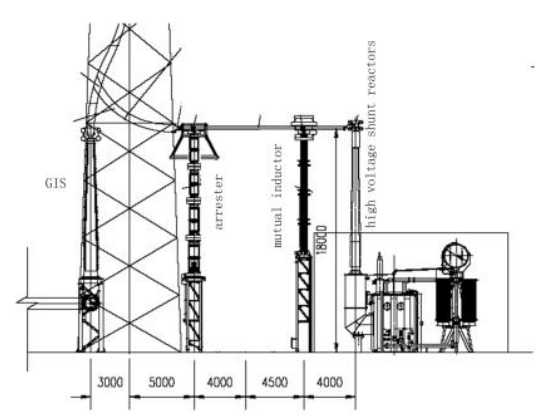

(a) 4 knobs

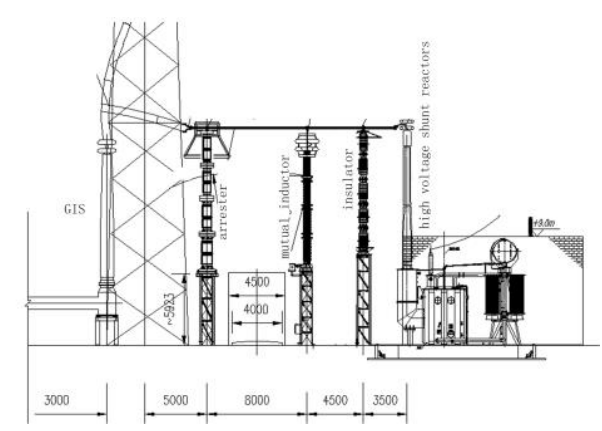

(b) 5 knobs

Fig. 1: Sectional view of HV reactor circuit system with 4 knobs and 5 knobs

In the circuit system, detailed name of single equipment, relevant support height and corresponding base frequency are as shown in Table 1, where the sectional resistance moment of the root of Lightning Arrester 1 and Insulator 1 is smaller than that of Lightning Arrester 2 and Insulator 2. To study the seismic coupling effect of UHV circuit system, a total of 4 analysis scenarios have been respectively derived from 4-knob option and 5-knob option according to the equipment types in this study. Detailed introduction and description of the various scenarios are given in Table 2. 
Table 1: Detailed name of single equipment, relevant support height and corresponding base frequency

\begin{tabular}{|c|c|c|c|}
\hline Name of equipment & Support height (m) & $\begin{array}{l}\text { Base frequency of single } \\
\text { equipment }(\mathrm{Hz})\end{array}$ & $\begin{array}{l}\text { Base frequency of "support + equipment" } \\
\text { system (Hz) }\end{array}$ \\
\hline Mutual inductor & 8.026 & 2.54 & 2.02 \\
\hline Lightning arrester 1 & 6.266 & 1.82 & 1.51 \\
\hline Lightning arrester 2 & 5.955 & 2.27 & 1.67 \\
\hline Insulator 1 & 7.750 & 1.78 & 1.72 \\
\hline Insulator 2 & 7.750 & 2.30 & 2.13 \\
\hline \multicolumn{4}{|c|}{ Table 2: Introduction of circuit scenarios } \\
\hline $\begin{array}{l}\text { Name of } \\
\text { scenario }\end{array}$ & \multicolumn{3}{|c|}{ Scenario introduction } \\
\hline Scenario 1 & \multicolumn{3}{|c|}{$\begin{array}{l}\text { 4-knob option: The circuit system is composed of Lightning Arrester } 1 \text { and mutual inductor as well as relevant } \\
\text { support and tubular busbar. }\end{array}$} \\
\hline Scenario 2 & \multicolumn{3}{|c|}{ 4-knob option: Lightning Arrester 2 is changed into on the basis of Scenario 1.} \\
\hline Scenario 3 & \multicolumn{3}{|c|}{$\begin{array}{c}\text { 5-knob option: The circuit system is composed of Lightning Arrester } 1 \text { and Insulator } 1 \text { as well as relevant support } \\
\text { and tubular busbar. }\end{array}$} \\
\hline Scenario 4 & \multicolumn{3}{|c|}{$\begin{array}{l}\text { 5-knob option: The supporting equipment are changed into Lightning Arrester } 2 \text { and Insulator } 2 \text { on the basis of } \\
\text { Scenario } 3 .\end{array}$} \\
\hline
\end{tabular}

ANSYS software is used to establish the numerical model for the circuit system. The flange connecting the equipment bottom and the support is simulated by using shell unit, and the equipment and flange are connected by using rigid rod. When modeling, the type of unit consistent with the various elements shall be used to simulate the circuit system as far as possible so that the numerical model can accurately reflect the true boundary condition of the structure. In the numerical model, flexible conductor coupling and flexible coupling of the circuit system are not considered. However, the flexible connecting fitting, tubular busbar termination equipment fitting and flexible conductor are added on the relevant positions in the circuit system in the form of concentrated mass unit. Numerical models developed for 4-knob and 5-knob options are as shown in Fig.2 and Fig. 3 respectively.

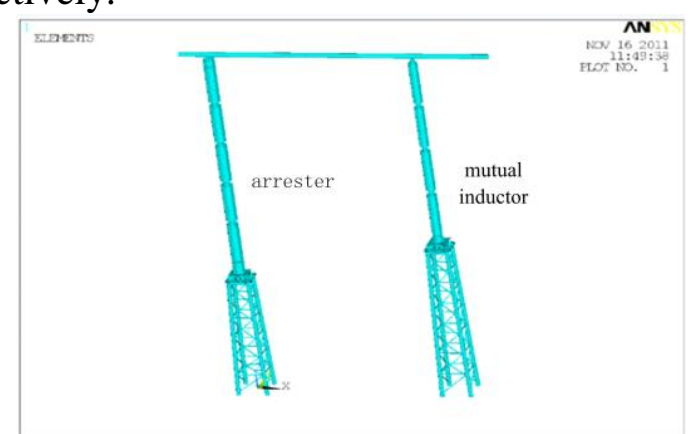

Fig. 2: Numerical model of lightning arrester and mutual inductor circuit system

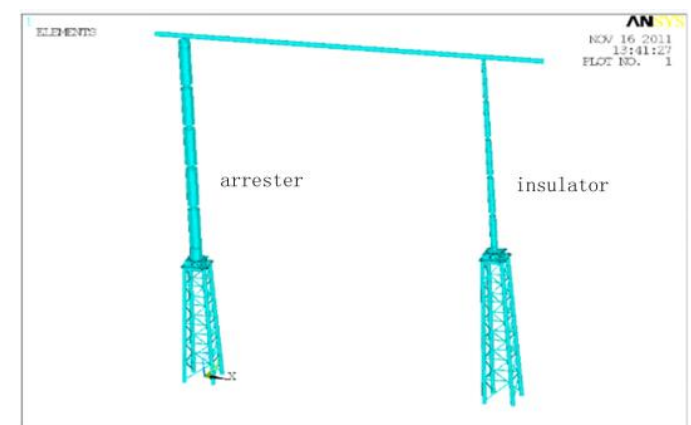

Fig. 3: Numerical model of lightning arrester and insulator circuit system

\section{Dynamic property analysis of coupling system}

Parameters of the various scenarios such as vibration mode and frequency, etc. can be obtained through modal analysis of the UHV reactor circuit system, so that a preliminary understanding of the dynamic characteristics and seismic capacity of the system can be realized. Table 3 shows the first 10 order modal analysis results of the circuit system, and Table 4 is a comparison of base frequency between the circuit system and the single equipment \& "support + equipment" system. It can be seen from the analysis results shown in the table that base frequency of the circuit systems of the various scenarios is lower than that of the relevant single equipment and "support + equipment" system. This indicates that after the various equipment are connected with the support and further connected with the tubular busbar and flexible conductor to for a circuit system by means of different forms of tubular busbar coupling fittings, overall rigidity of the circuit system is reduced by different degrees compared with the rigidity of single equipment and "support + equipment" system due to mutual coupling effects of the various equipment in the system. First-order vibration modes of the various scenarios are shown in Figs. 4. It can be seen from the vibration mode figures that the first-order 
vibration modes of the various scenarios all vibrate along the sliding direction of the tubular busbar and the vibrations are all overall vibrations.

Table 3: The first 10 order modal analysis result of various circuit system scenarios

\begin{tabular}{|c|c|c|c|c|}
\hline \multirow{2}{*}{ Order } & \multicolumn{4}{|c|}{ Frequency $(\mathrm{Hz})$} \\
\hline & Scenario 1 & Scenario 2 & Scenario 3 & Scenario 4 \\
\hline 1 & 1.38 & 1.55 & 1.27 & 1.49 \\
\hline 2 & 1.45 & 1.61 & 1.37 & 1.55 \\
\hline 3 & 1.87 & 1.87 & 1.51 & 1.66 \\
\hline 4 & 2.01 & 2.01 & 1.52 & 1.80 \\
\hline 5 & 6.05 & 6.03 & 4.24 & 4.27 \\
\hline 6 & 6.21 & 6.07 & 4.47 & 4.52 \\
\hline 7 & 7.08 & 6.49 & 6.38 & 6.33 \\
\hline 8 & 7.10 & 6.60 & 6.44 & 6.55 \\
\hline 9 & 7.46 & 7.45 & 6.95 & 6.59 \\
\hline 10 & 7.50 & 7.50 & 7.41 & 6.65 \\
\hline
\end{tabular}

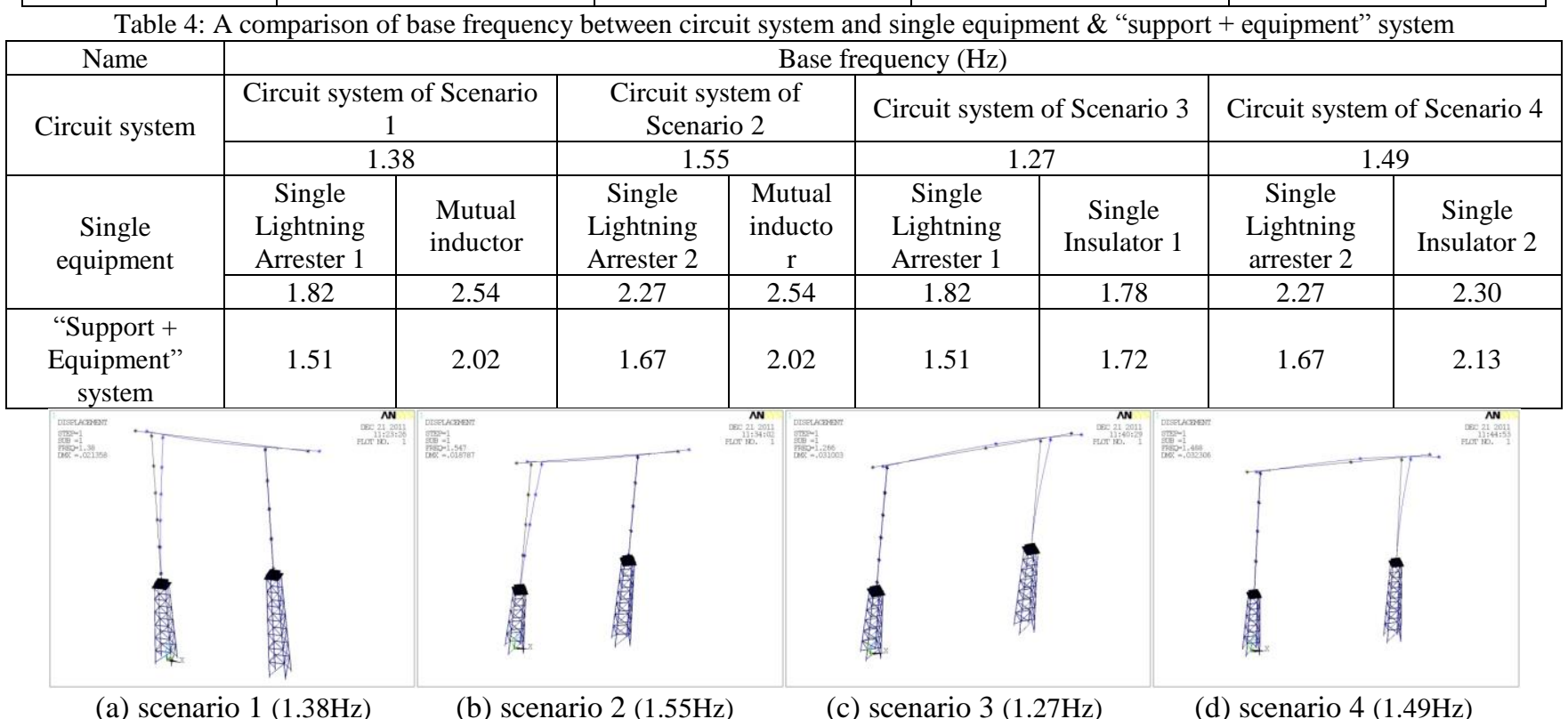

Fig. 4: 1st order vibration mode

\section{Seismic coupling effect analysis of coupling system}

On the basis of an analysis of the dynamic property of the coupling system, this chapter will, by taking establishment of a typical UHV circuit as an example, investigate the difference between the response pattern of UHV circuit coupling system under the action of earthquake as well as seismic capacity of single equipment.

4.1 Input condition. Seismic response of the coupling system is investigated by employing the response spectrum analysis method, and effort is made to ensure the masses participating in the modal superposition account for more than $90 \%$ of the total mass of relevant test condition. According to the requirements of "Code for Seismic Design of Electrical Installations" (GB50260-2013), the seismic acceleration response spectrum is formed based on an earthquake fortification intensity of 8 degrees and a characteristic period of $0.65 \mathrm{~s}$, and damping ratio of electrical equipment is taken as $2 \%$. The resulted seismic acceleration response spectrum curve is shown in Fig. 5. Predominant frequency range corresponding with the seismic acceleration response spectrum is $1.54 \mathrm{~Hz} \sim 10 \mathrm{~Hz}$, and the peak seismic acceleration beyond $10 \mathrm{~Hz}$ is on gradual attenuation. 


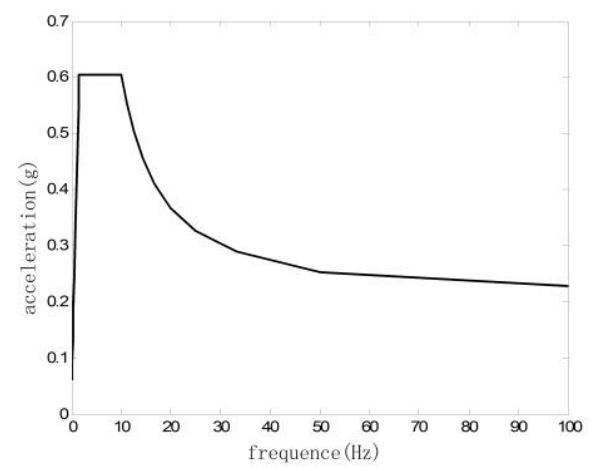

Fig. 5: Seismic acceleration response spectrum

4.2 Seismic capacity analysis. The difference in seismic capacity of circuit system equipment and single equipment is investigated according to the ratio of maximum stress of the equipment in the coupling system to that of the single equipment under the same earthquake testing condition. Table 5 is a comparison of seismic capacity between circuit system equipment and single equipment.

\begin{tabular}{|c|c|c|c|c|c|}
\hline \multirow{2}{*}{ Name of scenario } & \multirow{2}{*}{ Name of equipment } & \multicolumn{2}{|c|}{ Equipment stress (MPa) } & \multicolumn{2}{|c|}{$\begin{array}{l}\text { Ratio of circuit system } \\
\text { equipment stress to single } \\
\text { equipment stress }\end{array}$} \\
\hline & & $\begin{array}{c}\text { Earthquake } \\
\text { in Direction } \\
\text { X }\end{array}$ & $\begin{array}{l}\text { Earthquake } \\
\text { in Direction } \\
\mathrm{Y}\end{array}$ & $\begin{array}{c}\text { Earthquake in } \\
\text { Direction X }\end{array}$ & $\begin{array}{c}\text { Earthquake } \\
\text { in Direction } \\
\mathrm{Y}\end{array}$ \\
\hline \multirow{2}{*}{ Scenario 1} & Lightning arrester 1 & 24.66 & 26.23 & 1.07 & 1.14 \\
\hline & Mutual inductor & 22.29 & 20.49 & 1.21 & 1.11 \\
\hline \multirow{2}{*}{ Scenario 2} & Lightning arrester 2 & 22.10 & 22.74 & 1.29 & 1.32 \\
\hline & Mutual inductor & 22.31 & 19.54 & 1.21 & 1.06 \\
\hline \multirow{2}{*}{ Scenario 3} & Lightning arrester 1 & 24.96 & 26.52 & 1.09 & 1.15 \\
\hline & Insulator 1 & 26.66 & 20.79 & 1.20 & 0.94 \\
\hline \multirow{2}{*}{ Scenario 4} & Lightning arrester 2 & 20.74 & 23.14 & 1.21 & 1.35 \\
\hline & Insulator 2 & 26.27 & 17.71 & 1.52 & 1.02 \\
\hline \multicolumn{4}{|c|}{ Mean ratio of circuit system equipment stress to single equipment stress } & 1.23 & 1.14 \\
\hline \multirow{5}{*}{ Single equipment } & Lightning arrester 1 & \multicolumn{2}{|c|}{22.97} & \multicolumn{2}{|c|}{1.00} \\
\hline & Lightning arrester 2 & \multicolumn{2}{|c|}{17.19} & \multicolumn{2}{|c|}{1.00} \\
\hline & Insulator 1 & \multicolumn{2}{|c|}{22.18} & \multicolumn{2}{|c|}{1.00} \\
\hline & Insulator 2 & \multicolumn{2}{|c|}{17.33} & \multicolumn{2}{|c|}{1.00} \\
\hline & Mutual inductor & \multicolumn{2}{|c|}{18.40} & \multicolumn{2}{|c|}{1.00} \\
\hline
\end{tabular}

The following can be seen from the above analysis:

(1) Under the action of Direction X earthquake, stress of the equipment in Scenarios 1 through 4 has a magnification coefficient ranging from 1.07 to 1.52 as opposed to stress of single equipment.

(2) Under the action of Direction Y, stress of the equipment in Scenarios 1 through 4 has a magnification coefficient ranging from 0.94 to 1.35 as opposed to stress of single equipment.

(3) After different equipment and support systems are connected together to form a circuit system by means of tubular busbar, fitting and flexible conductor, etc., stress of the equipment in the circuit system is on the increase under the action of earthquake as opposed to that of single equipment. Under the action of earthquake in Direction X and Direction Y, the mean stress magnification coefficient of the equipment in Scenarios 1 through 4 as opposed to single equipment is respectively 1.23 and 1.14.

In general, the seismic capacity of the interconnected equipment in UHV circuit system is different from that of the single equipment due to the influence of a number of factors including weights of support and auxiliary structure, tubular busbar and flexible conductor, etc., which results in the response of the equipment in the circuit system under the action of earthquake is magnified in different degrees as opposed to single equipment. Causes to such phenomenon can be summarized and mainly reflected on the following aspects:

(1) The overall structure formed by the equipment and support may cause the base frequency of the overall structure to be different from that of single equipment due to varied structural form and rigidity, which impacts the seismic capacity of the equipment under the action of earthquake. 
(2) It can be known from the characteristics of UHV circuit system that under normal circumstance, when one end of the tubular busbar is connected with the equipment by means of tubular busbar fixed fitting, the other end should be connected with the equipment by means of tubular busbar sliding fitting or flexible conductor. In case of any seismic effect along the tubular busbar direction, the equipment connected with tubular busbar by means of tubular busbar fixed fitting would be subject to seismic effect resulted from mass of auxiliary structures and tubular busbar.

(3) Under the action of earthquake, equipment connected with tubular busbar by means of flexible coupling fitting and flexible conductor would have a certain traction on the tubular busbar, thus impacting the seismic capacity of the equipment supporting the circuit system. Furthermore, such auxiliary structures would add to the weight supported by the equipment top end, and add to seismic response of the equipment as well.

(4) Due to interaction between equipment, equipment having different dynamic characteristics under the action of earthquake would impact each other, causing equipment having a bigger inter-equipment displacement to pull at the equipment having a smaller displacement.

\section{Seismic requirements of single equipment}

The impact of mass of the support and the auxiliary structural elements in the circuit system on equipment seismic capacity is investigated by taking the equipment and support in Scenario 1 and Scenario 4 as an example, which provides a reference suggestion for the seismic capacity evaluation of UHV equipment. The analysis results are given in Tables $6 \& 7$, in which the mass is applied to the relevant positions on the top end of the equipment when it comes to the weights of tubular busbar and fittings in the circuit system.

Table 6: Seismic capacity analysis of circuit system of Scenario 1: Lightning arrester 1 and mutual inductor + support

\begin{tabular}{|c|c|c|}
\hline Test condition analyzed & Equipment bottom stress (Mpa) & $\begin{array}{c}\text { Stress magnification as opposed to } \\
\text { single equipment }\end{array}$ \\
\hline Mutual inductor + Support & 22.11 & 1.20 \\
\hline Lightning arrester 1+ Support & 24.78 & 1.08 \\
\hline $\begin{array}{c}\text { Mutual inductor + Support + (Tubular busbar, fitting) } \\
\text { weight }\end{array}$ & 24.50 & 1.33 \\
\hline $\begin{array}{c}\text { Lightning arrester 1+ Support + (Tubular busbar, } \\
\text { fitting) weight }\end{array}$ & 24.84 & 1.08 \\
\hline
\end{tabular}

Table 7: Seismic capacity analysis of circuit system of Scenario 4: Lightning arrester 2 and Insulator $2+$ support

\begin{tabular}{|c|c|c|}
\hline Test condition analyzed & Equipment bottom stress (Mpa) & $\begin{array}{c}\text { Stress magnification as opposed to } \\
\text { single equipment }\end{array}$ \\
\hline Insulator 2 + Support & 20.25 & 1.17 \\
\hline Lightning arrester 2 + Support & 20.55 & 1.20 \\
\hline Insulator 2 + Support + (Tubular busbar, fitting) weight & 24.64 & 1.42 \\
\hline $\begin{array}{c}\text { Lightning arrester 2+ Support +(Tubular busbar, fitting) } \\
\text { weight }\end{array}$ & 22.11 & 1.29 \\
\hline
\end{tabular}

It can be seen from the above analysis that the weight of equipment support, circuit system connection and the various structural elements in the connecting circuit would all add to the response of the equipment under the action of earthquake. Looking from the analysis result of this example, the stress magnification of support on the equipment may reach 1.2, and when the weight of tubular busbar and fitting in the circuit system is taken into account, the stress magnification of the equipment may reach 1.42. Therefore, when evaluating seismic capacity of the equipment, consideration should be given to the support dynamic magnification of the equipment and weight of the connecting structural elements of the circuit system on top of single equipment. Meanwhile, the following factors should also be taken into consideration:

(1) Wind load impact should be considered. When conducting a seismic capacity test on single equipment, relevant design wind load should be taken into account.

(2) Impact of intensity of pressure inside the equipment should be considered. Some equipment has internal intensity of pressure under normal working condition, which must be considered during seismic capacity test. 
(3) Impact of tensile forces of fittings and conductors should be considered. If, during operation, there is any force acting on the equipment by fittings or conductors connecting with it, the impact of such factor should be taken into account during seismic capacity analysis.

It can be seen from the comparative analysis of the circuit seismic capacity versus single equipment seismic capacity that when the impact of the support and the auxiliary elements in the circuit system is taken into consideration, the seismic capacity analysis results of the equipment and the equipment in the circuit are similar. And in actual engineering design, according to the previous research results, the seismic capacity evaluation of single equipment by applying the 1.4 dynamic signification coefficient of the support to UHV equipment and then taking into account the various parameters of the circuit system and impact of external loads is somewhat safe and reasonable.

\section{Conclusions}

Numerical models of typical UHV circuit systems have been established by using the finite element analysis software ANSYS, and a comparison has been made between the dynamic characteristics and seismic capacity of the circuit system versus single equipment in order to identify the difference in seismic capacity between single equipment and circuit system coupling equipment. As a result, the following conclusions are drawn:

(1) Dynamic properties of the coupling system of UHV circuit is related to the coupling method used between the equipment in the circuit, the tubular busbar rigidity, tubular busbar span, support rigidity and mechanical properties of the equipment among other factors. The aforementioned factors all cause the base frequency of the circuit system to be lower than that of single equipment.

(2) After different equipment and support systems are connected together to form a circuit system by means of tubular busbar, fitting and flexible conductor, etc., stress of the equipment in the circuit system is on the increase under the action of earthquake as opposed to that of single equipment. In general, the ratio of stress of the equipment in the circuit system to the stress of single equipment can be up to 1.2 or more.

(3) Seismic capacity analysis of single equipment only can no longer meet the practical needs of UHV engineering. If the seismic capacity of the equipment in the circuit system is still evaluated according to the seismic capacity criteria of single equipment, potential safety hazard will no doubt be left behind. In practical engineering, when evaluating the seismic capacity of the circuit system based on the seismic capacity of single equipment, stresses produced by a number of factors must be taken into consideration on a comprehensive basis, which include coupling method of combination support and fitting, weight of various coupling elements, conductor tensile force, intensity of pressure inside equipment and design wind load, etc.

\section{Acknowledgment}

This work is supported by State Grid Corporation of China support project, Seismic performance optimization technology research on pillar type electrical equipment and converter loop system of UHV converter substation (GCB17201500063).

\section{References}

[1] GB50260-2013, Code for Seismic Design of Electrical Installations[S]. China Planning Press, 2013.

[2] GB50010-2010, Code for Seismic Design of Buildings[S]. Beijing: China Architecture \& Building Press, 2010.

[3] Hu Yuxian. Earthquake Engineering[M]. Beijing: Seismological Press, 2006.

[4] Dai Zebing; Zhu Zhubing; Wang Gang; Zhao Heng. Seismic Design Research on UHV Transformation Equipment based on Different Codes. Paper Collection "New Situation, New 
Challenges - Forum 2009 on Implementation of Scientific Development Concept by Civil Construction of Electric Power", 2009.

[5] Research Institute of Power Transmission \& Transformation Engineering Mechanics, China Electric Power Research Institute, Seismic Study Report on UHV Reactor Circuit, 2011,10.

[6] Hu Yujing; Xie Qiang. Seismic Vulnerability Analysis of Tubular Busbar Connected Substation Electrical Equipment. Electric Power Construction, Vol.31 (7), 2010,7.

[7] Armen Der Kiureghian, Jerome L.Sackman, Kee-Jeung Hong. Interaction in Interconnected Electrical Substation Equipment Subjected to Earthquake Ground Motions. A report to sponsor Pacific Gas\&Electric Co. San Francisco, California. 